\title{
New Managing Editor
}

We are pleased to announce the appointment of Cathyann Colaiezzi of ICDD as Managing Editor for Powder Diffraction effective with this issue. Cathyann came to ICDD in October 2000 as an Editorial Assistant and moved on to become Desktop Publishing Coordinator in April 2002. As Managing Editor, Cathyann will take on additional responsibilities. She will be responsible for non-technical matter for Powder Diffraction and for communication with the journal publisher, the American Institute of Physics (AIP). All final manuscripts after formally accepted by the Editor-in-Chief will be sent to her to be prepared for records and for final transfer to AIP for processing and printing. Cathyann looks forward to working with everyone associated with Powder Diffraction.

We would like to thank Tim Jenkins for having served as Managing Editor in 2003.

Ting C. Huang

Editor-in-Chief

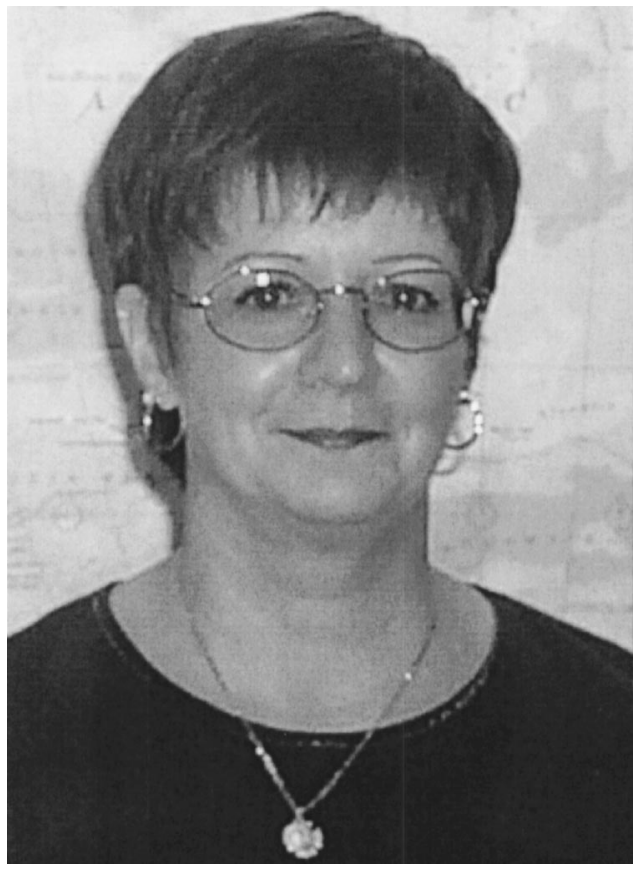

